\title{
A paradoxical change in economic inequality in presenting visual acuity between 2009 and 2014: a nonuseful decline
}

Asieh Mansouri, ${ }^{1}$ Mohammad Hassan Emamian, ${ }^{2}$ Hojjat Zeraati, ${ }^{3}$ Hassan Hashemi ${ }^{4}$ and Akbar Fotouhi ${ }^{5}$

${ }^{1}$ Hypertension Research Center, Cardiovascular Research Institute, Isfahan University of Medical Sciences, Isfahan, Islamic Republic of Iran. ${ }^{2}$ Ophthalmic Epidemiology Research Center, Shahroud University of Medical Sciences, Shahroud, Islamic Republic of Iran. ${ }^{3}$ Department of Epidemiology and Biostatistics, School of Public Health, Tehran University of Medical Sciences, Tehran, Islamic Republic of Iran. ${ }^{4}$ Noor Ophthalmology Research Center, Noor Eye Hospital, Tehran, Islamic Republic of Iran. ${ }^{5}$ Department of Epidemiology and Biostatistics, School of Public Health, Tehran University of Medical Sciences, Tehran, Islamic Republic of Iran (Correspondence to: A. Fotouhi: afotouhi@tums.ac.ir).

\begin{abstract}
Background: Despite the widespread literate on health inequalities and their determinants, changes in health inequalities over time have not received enough attention.

Aims: To measure and decompose the over-time changes in economic inequality in presenting visual acuity measured using Logarithm of the Minimum Angle of Resolution.

Methods: We analysed 4706 participants who had complete data on presenting visual acuity and economic status in 2009 and 2014 in the Shahroud Eye Cohort Study. We measured changes in presenting visual acuity concentration indices and decomposed them the using a longitudinal approach.

Results: Both the presenting visual acuity and economic status deteriorated between 2009 and 2014. The mean (standard deviation) for presenting visual acuity and economic status scores in 2009 versus 2014 were 0.090 (0.2) versus 0.103 (0.2) and 0.01 (1.0) versus 0.0005 (1.07), respectively. Presenting visual acuity concentration index (95\% confidence interval) in the first versus second phases of the study were $-0.245(-0.212$ to -0.278$)$ versus $-0.195(-0.165$ to -0.225$)$, respectively. Longitudinal decomposition of this change in concentration indices during the 5 -year period indicated that the most important contributor to reduction in economic inequality of presenting visual acuity was deterioration of presenting visual acuity among people with higher economic status due to their ageing.

Conclusion: Unexpectedly, reduction in economic inequality in presenting visual acuity was due to presenting visual acuity deterioration among the higher economic status group rather than its amelioration among the lower economic status group. Therefore, the needs of all socioeconomic groups should be considered separately to modify presenting visual acuity in each group and, consequently, reduce the economic inequality in presenting visual acuity.

Keywords: health inequality, economic inequality, longitudinal analysis, presenting visual acuity, socioeconomics

Citation: Mansouri A; Emamian MH; Zeraati H; Hashemi H; Fotouhi A. A paradoxical change in economic inequality in presenting visual acuity between 2009 and 2014: a nonuseful decline. East Mediterr Health J. 2021;27(7):679-686. https://doi.org/10.26719/emhj.21.020

Received: 28/12/19; accepted: 02/11/20

Copyright (C) World Health Organization (WHO) 2021. Open Access. Some rights reserved. This work is available under the CC BY-NC-SA 3.o IGO license (https://creativecommons.org/licenses/by-nc-sa/3.o/igo)
\end{abstract}

\section{Introduction}

Evaluation of over-time changes in health inequalities and understanding determinants of these changes are key policy objectives for all governments (1). The condition-dependent nature of health necessitates analysis of health inequality changes over time using dynamic models based on longitudinal data (2). However, most previous studies have analysed changes in health inequalities using repeated cross-sections and static regression models (3-7). Decomposition of health inequalities using these static models cannot reveal dynamic links between health and its determinants (8).

We used the data collected in a cohort study and applied a dynamic decomposition method (8) to analyse the longitudinal changes in economic inequality in presenting visual acuity (PVA), as one of the health outcomes that have a strong and fully proved relationship with socioeconomic status (7,9-14). All of the previous studies were of a cross-sectional nature without paying attention to the changes occurring over time. To the best of our knowledge, after the study by Allanson et al. (8), this is the first study to use the cohort data to conduct a longitudinal analysis of changes in inequality. By revealing the process of changes in inequalities over time and identifying the factors influencing such changes, we can provide health policy-makers with effective recommendations to design programmes and policies aimed at reducing these inequalities.

\section{Methods}

\section{Study design}

This study was performed using data collected by the Shahroud Eye Cohort Study (ShECS) (15). Among 6311 people who were invited to participate in ShECS, 5190 (82.2\%) participated in the first phase of the study in 2009. Of these, 453 people were removed from the second phase of the study in 2014 due to death, immigration or reluctance 
to continue. Thus, in the second phase, the examinations were performed on 4737 people (91.27\%). Further details about ShECS are presented elsewhere (15).

In the present study, PVA, defined as vision in normal daily life conditions, whether corrected or not, was the outcome variable. In ShECS, this quantitative variable was measured using the Logarithm of the Minimum Angle of Resolution (LogMar). On this scale, a higher score means poorer vision. To cover the data for both eyes, the outcome variable was set as the PVA score in the better eye. Other studied variables were: age, sex, education (number of successfully completed years of education), marital status (married or unmarried), occupation (retired or not retired), diabetes, hypertension, smoking, medical insurance, body mass index and household assets.

\section{Ethical approval}

This study was approved by the Ethics Committee of Tehran University of Medical Sciences. ShECS, which was used as the source of data for present study, had been approved by the Ethics Committee of Shahroud University of Medical Sciences (Registration Code: IRB 8737).

\section{Statistical analysis}

\section{Principal component analysis}

Principal component analysis (PCA) was used to convert the variables used for the assessment of household assets into a quantitative variable, economic status (ES) score. Prior to PCA, the homogeneity of asset variables was measured using the Kaiser-Meyer-Olkin Measure of Sampling Adequacy and Bartlett's Sphericity Test. The Kaiser-Meyer-Olkin index for the first and second phases of the study was 0.735 and 0.726 , respectively. Bartlett's Sphericity Test was significant for both phases $(\mathrm{P}<$ 0.001). Therefore, according to Williams et al. (16), home asset variables in both phases of the study were relevant and proper for the PCA. As a result, PCA was conducted on home assets in the first and second phases. As previously described (7), the ES variables in the first and second phases were formed by weighting the first component, which justified the highest variance in asset data (17).

\section{Measuring inequality}

Concentration index was calculated as twice the covariance between the outcome variable and the fractional rank in the socioeconomic status indicator variable divided by the mean of the outcome (18), and was used to measure economic inequalities in PVA and other variables. Computational details are presented in the Appendix section.

\section{Decomposition of changes in the economic inequality in PVA by a dynamic method}

When using a dynamic method, it is necessary only to use the longitudinal or follow-up data (8). This analysis must be performed only on the subjects with registered data on both the outcome and socioeconomic status variables. People who had no registered data on PVA or home assets in one or both phases of the study were excluded from the analysis. Accordingly, a total of 482 people were excluded and the data collected on 4706 people were used in the analyses.

The decomposition of the change in inequality in this method was a hierarchical process. To simplify, we divided this process into two parts: nondeterministic decomposition and deterministic decomposition. In nondeterministic decomposition, the changes in the concentration indices between the two periods were decomposed using the following equation:

$$
\Delta C I=M^{R}-M^{H}
$$

where, $M^{R}$ was the health-related income mobility and $M^{H}$ income-related health mobility. Therefore, this equation implied that changes in inequality in an outcome over time resulted from changes in the health status of poor and wealthy people (health mobility) and changes in the positions of healthy and unhealthy individuals in income distribution (income mobility). Accordingly, $M^{H}$ showed whether changes in health were favourable for poor or rich people. $M^{R}$ showed whether changes in income were favourable for healthy or unhealthy people.

After determining the value of $M^{\mathrm{H}}\left(M^{\mathrm{PVA}}\right.$ in this study), it was necessary to decompose it in order to identify the share of changes in income (ES in this study) and other determinants in it via deterministic decomposition. The following steps were used for this decomposition. (1) Identifying short-run determinants of PVA change (determinants of changes in PVA from the first to second phase) using the Error Correction Model (ECM). This model allowed for lagged as well as contemporaneous responses to changes in ES and other PVA determinants. (2) Computing expected PVA in the equilibrium-steady state that was called long-run or equilibrium PVA function (PVA ). (3) Computing equilibrium error, value of adjustment PVA in first phase toward PVA*, $\left(\mathrm{PVA}^{*}\right.$ - PVA $\left.{ }^{\text {phase }}{ }^{1}\right)$. (4) Identifying long-run determinants of PVA change (determinants of equilibrium error). (5) Determining the contribution of short-run and longrun determinants of PVA changes in PVA mobility and consequently PVA inequality changes (more details on statistical analysis are presented in the Appendix).

Mathematically, it was possible to decompose $M^{R}\left(M^{E S}\right.$ in this study) and determine the contribution of determinants in the health-related income rank of individuals. Since the determinants of income variations are not routinely collected in health research, it was not possible to conduct such an analysis in the present study.

\section{Results}

The mean PVA (95\% confidence interval; CI), measured based on the LogMAR scale, was $0.090(0.084-0.096)$ and $0.103(0.098-0.109)$ in the first and second phases of the study, respectively $(P<0.001)$. 
The mean (standard deviation; SD) for age, education and body mass index in the first versus second phases of the study were 50.9 (6.2) versus 55.9 (6.2), 7.3 (4.7) versus 7.3 (4.7), and 28.4 (4.9) versus 28.9 (5.0), respectively. Table 1 presents the status of other independent variables in the first and second phases of the study. Comparing the data collected in the first and second phases, we observed a reduction in the number of individuals in the married subgroup and an increase in the retired subgroup during the study. The number of people with diabetes and hypertension nearly doubled during the study. There was also an increase in the number of insured people and smokers.

We constructed economic quintiles in each phase by dividing the ES into 5 groups. The distribution of people in economic quintiles in the first versus second phases of the study is shown in Figure 1. Due to the existence of tied data (observations having the same value) created by PCA, particularly in the first phase, the percentages differ from $20 \%$ for some quintiles.

The PVA concentration index ( $95 \% \mathrm{CI})$ in the first and second phases of the study was $-0.245(-0.212$ to -0.278$)$ and $-0.195(-0.165$ to -0.225$)$, respectively. Comparing these concentration indices indicated that economic inequality in PVA decreased by 0.05 between 2009 and 2014.

According to the nondeterministic decomposition of concentration indices changes during the 5 -year period, $M^{P V A}$ and $M^{E S}$ were -0.08 and -0.03 , respectively. The negative values of $M^{\mathrm{PVA}}$ indicates that the deterioration of visual acuity between 2009 and 2014 was more concentrated among people with better economic status. In contrast, the negative value of $M^{\mathrm{ES}}$ showed that the deterioration of economic status during the study was more concentrated among people with poorer visual acuity score.

As the first step of deterministic decomposition of $M^{\mathrm{PVA}}$, an ECM was run to identify short-run determinants of PVA changes. The variables that were entered into the final model are presented in the column 1 of Table 2. In line with the results of Allanson et al. (2), the significance level for the final model was set at 0.1. According to this model, improving ES and achieving control of hypertension in the second phase as compared with the first phase, and education and ES in the first phase prevented an increase in PVA. However, deterioration of ES and development of hypertension in the second phase as compared with the first phase, and age, diabetes and hypertension in the first phase helped to increase PVA in the second phase. The next step was to determine long-run or equilibrium PVA function $\left(\mathrm{PVA}^{*}\right)$. The determinants of $\mathrm{PVA}^{*}$ (presented in column 2 of Table 2 ) were obtained by dividing the coefficients of the baseline values of the variables in the ECM by the value of $\lambda$ (absolute value of regression coefficient for PVA in the first phase). These coefficients represented estimates of the long-term effects of determinants on PVA changes.
After identifying the determinants of $\mathrm{PVA}^{*}$, we used the coefficients of these determinants and calculated PVA* for each person. The mean (SD) PVA* was 0.235 (0.204). Since the PVA increased in the second phase compared to the first phase, the change that occurred in the mean PVA from the first to the second phase narrowed the gap between PVA in first phase (initial PVA) and PVA*.

The results of $M^{\mathrm{PVA}}$ decomposition are presented in Table 3. According to Allanson et al. (8), only the factors whose changes between the 2 periods were significant in the ECM were used to calculate the contribution of the first component, the short-run determinants. Therefore, only 2 variables, changes in hypertension and changes in ES played a role in the first component. The total share of this component was $-7.50 \%$. Therefore, short-run changes in hypertension and ES contributed to the reduction in $M^{\mathrm{PVA}}$ and consequent increment in PVA inequality.

The second component, long-run determinants (determinants of adjustment of initial PVA toward PVA*), made a considerable contribution to changes in PVA inequality. In this component, the long-run changes in age, diabetes and hypertension helped to increase $M^{\text {PVA }}$ and consequently reduce the economic inequality in PVA. On the contrary, the long-run changes in education and ES helped to reduce $M^{\mathrm{PVA}}$ and consequently increase inequality in PVA. The long-run determinants of PVA

Table 1 Characteristics of participants in Shahroud Eye Cohort Study 2009-2014

\begin{tabular}{lcc} 
Variable & \multicolumn{2}{c}{ Year } \\
& $\mathbf{2 0 0 9}$ & $\mathbf{2 0 1 4}$ \\
& No. (\%) & No. (\%) \\
Married & $4354(92.5)$ & $4215(89.6)$ \\
Occupation (retired) & $763(16.2)$ & $1276(27.1)$ \\
Diabetes & $575(12.2)$ & $1117(23.9)$ \\
Hypertension & $1799(38.2)$ & $2902(61.7)$ \\
Cigarette smoking & $566(12.0)$ & $671(14.3)$ \\
Medical insurance & $4435(94.9)$ & $4636(98.5)$ \\
Household assets: & & \\
Car & $3009(63.9)$ & $3303(70.2)$ \\
Motorcycle & $1442(30.6)$ & $1019(21.7)$ \\
TV/LED/LCD & $4688(99.6)$ & $4679(99.4)$ \\
Bathroom & $4689(99.6)$ & $4682(99.5)$ \\
Vacuum cleaner & $4545(96.6)$ & $4614(98.1)$ \\
Washing machine & $4217(89.6)$ & $4471(95.0)$ \\
Refrigerator & $4692(99.7)$ & $4687(99.6)$ \\
Computer & $2953(62.7)$ & $2942(62.5)$ \\
Telephone & $4660(99.0)$ & $4573(97.2)$ \\
Microwave & $421(9.0)$ & $547(11.6)$ \\
Dishwasher & $271(5.8)$ & $379(8.1)$ \\
Freezer & - & $2940(62.5)$ \\
Internet access ${ }^{\mathrm{a}}$ & - & $1909(40.6)$ \\
Internet in home & & $2081(44.2)$ \\
\hline
\end{tabular}

${ }^{a}$ Did not measure in first phase of study. 
Figure 1 Distribution of people by economic quintiles in 2009 and 2014, Shahroud, Islamic Republic of Iran.

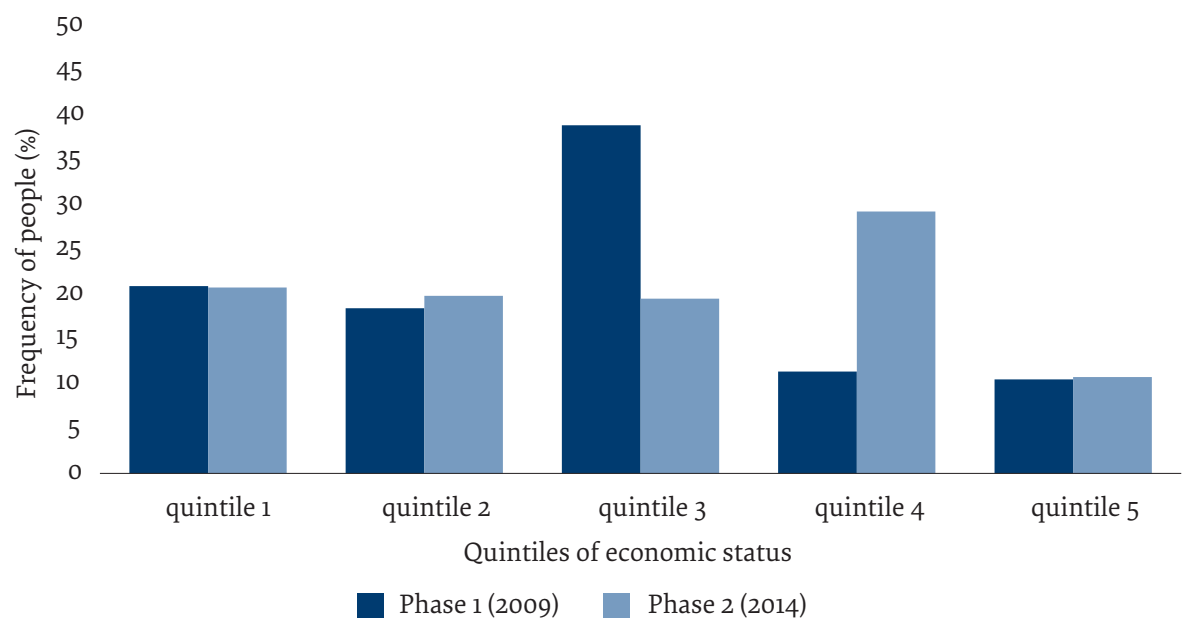

changes contributed to the increment in $M^{\text {PVA }}$ and consequent reduction in PVA inequality.

Considering that the mean $\mathrm{PVA}^{*}$ was higher than the mean PVA in the first phase, the larger gap between the 2 scores indicated a more favourable condition. The mean (SD) gap between PVA* and PVA in the first phase in terms of economic quintiles is presented in Figure 2. This shows that the gap was larger in poorer than richer economic groups. In other words, there was a higher level of adjustment toward the equilibrium steady state in rich economic groups. This finding is consistent with the interpretation of the sum of the effects of the second component in Table 3 (adjustment toward PVA*).

Table 2 Determinants of PVA change during 5 years by Error Correction Model and the implied equilibrium PVA function, Shahroud, Islamic Republic of Iran, 2009-2014

\begin{tabular}{|c|c|c|c|}
\hline \multirow[t]{2}{*}{ Variables } & \multicolumn{2}{|c|}{ Error Correction Model } & \multirow{2}{*}{$\begin{array}{c}\text { Equilibrium PVA function } \\
\text { Coefficient }^{\mathrm{a}}\end{array}$} \\
\hline & Coefficient & $95 \% \mathrm{CI}$ & \\
\hline \multicolumn{4}{|l|}{ Hypertension changes } \\
\hline Unchanged & Reference & & \\
\hline Developing & 0.0001 & $-0.0095,0.0098$ & \\
\hline Achieving control & $-0.0182^{* *}$ & $-0.0352,-0.0012$ & \\
\hline \multicolumn{4}{|l|}{ ES changes } \\
\hline Unchanged & Reference & & \\
\hline Becoming poorer & 0.0016 & $-0.0097,0.0129$ & \\
\hline Becoming richer & $-0.0153^{* * *}$ & $-0.0259,-0.0048$ & \\
\hline PVA 2009 & $-0.4110^{* * *}$ & $-0.5136,-0.3084$ & \\
\hline Age 2009 (years) & $0.0013^{* * *}$ & $0.0004,0.0023$ & 0.0032 \\
\hline Education (years) 2009 & $-0.0015^{* *}$ & $-0.0028,-0.0003$ & -0.0036 \\
\hline Diabetes 2009 & $0.0343^{* * *}$ & $0.0140,0.0550$ & 0.0834 \\
\hline Hypertension 2009 & $0.0092^{*}$ & $-0.0016,0.0201$ & 0.0224 \\
\hline \multicolumn{4}{|l|}{ Economic quintiles 2009} \\
\hline First (poorest) & Reference & & Reference \\
\hline Second & $-0.0198^{* * *}$ & $-0.0332,-0.0063$ & -0.0482 \\
\hline Third & -0.0058 & $-0.0192,0.0074$ & -0.0141 \\
\hline Fourth & $-0.0137^{*}$ & $-0.0287,0.0013$ & -0.0333 \\
\hline Fifth (richest) & $-0.0188^{* *}$ & $-0.0349,-0.0026$ & -0.0457 \\
\hline Constant & 0.0014 & $-0.0450,0.0477$ & 0.0034 \\
\hline
\end{tabular}

${ }^{*} \mathrm{P}<1 \%,{ }^{* *} \mathrm{P}<5 \%$ and ${ }^{* * *} \mathrm{P}<10 \%$

aThese coefficients were obtained by dividing the coefficients of the baseline values of the variables in the Error Correction Model by the absolute value of PVA regression coefficient in the first phase in this model (0.4110).

$E S=$ economic status; $P V A=$ presenting visual acuity 


\begin{tabular}{|c|c|c|c|}
\hline Component & Variable & Mobility index & Percentage contribution to $M^{\mathrm{PVA}}(\%)$ \\
\hline \multirow[t]{9}{*}{ Short-run determinants } & \multicolumn{3}{|c|}{ Hypertension changes } \\
\hline & \multicolumn{3}{|l|}{ Unchanged (reference) } \\
\hline & Developing & -0.0001 & 0.12 \\
\hline & Controlling & 0.0021 & -2.62 \\
\hline & \multicolumn{3}{|c|}{ Economic status changes } \\
\hline & \multicolumn{3}{|l|}{ Unchanged (reference) } \\
\hline & Becoming poorer & -0.0021 & 2.62 \\
\hline & Becoming richer & 0.0061 & -7.62 \\
\hline & Sum & 0.0060 & -7.50 \\
\hline \multirow{12}{*}{$\begin{array}{l}\text { long-run determinants } \\
\text { (adjustment to equilibrium) }\end{array}$} & Age 2009 & -0.1538 & 192.25 \\
\hline & Education (years) & 0.0457 & -57.12 \\
\hline & Diabetes 2009 & -0.0082 & 10.25 \\
\hline & Hypertension 2009 & -0.0073 & 9.12 \\
\hline & \multicolumn{3}{|c|}{ Economic status 2009} \\
\hline & \multicolumn{3}{|l|}{ First Q (reference) } \\
\hline & Second Q & -0.0054 & 6.75 \\
\hline & Third Q & 0.0092 & -11.50 \\
\hline & Fourth Q & 0.0139 & -17.38 \\
\hline & Fifth Q & 0.0217 & -27.13 \\
\hline & Constant & -0.0032 & 4.00 \\
\hline & Sum & -0.0874 & 109.25 \\
\hline Total explained & & -0.0814 & 101.75 \\
\hline Residual & & 0.0014 & -1.75 \\
\hline Total & & -0.0800 & 100.0 \\
\hline
\end{tabular}

$E S=$ economic status; $P V A=$ presenting visual acuity; $M^{\text {PVA }}=$ ES-related PVA mobility index; $Q=$ quintile.

\section{Discussion}

The results of measuring the economic inequality in PVA indicated that the PVA had a higher level of concentration among people with lower ES. This finding has also been reported by many other studies $(9,10,19,20)$.

The present study showed that the economic inequality in PVA decreased by 0.05 between 2009 and 2014. This change in the economic inequality in PVA was decomposed by a longitudinal dynamic method. In nondeterministic decomposition, $M^{\text {PVA }}$ was -0.08. This index shifted towards decreasing the economic inequality in PVA in the population. $M^{\mathrm{ES}}$ was -0.03. Therefore, this index moved toward increasing the economic inequality in PVA in the population. Because of the positive correlation between ES and health, this index is reported negative in most studies (21). Thus, $M^{\mathrm{PVA}}$ and $M^{\mathrm{ES}}$ moved toward decreasing and increasing the economic inequality in PVA, respectively. Eventually, in this bilateral struggle, $M^{\mathrm{PVA}}$ dominated and reduced inequality in PVA.

The results of $M^{\text {PVA }}$ decomposition showed that the contribution of the changes in hypertension and ES during the study was positive. Therefore, the changes in these 2 variables contributed to increasing the economic inequality in PVA. This was because the number of people who developed hypertension during the study was significantly higher than the number who achieved control of hypertension during the same period. The increase in PVA of people who developed hypertension during this time was 3.04 times higher than the number who recovered from hypertension during the same period. A high percentage of people whose ES remained unchanged during the study belonged to the first and second economic quintiles. There are confirmed relationships between hypertension and visual impairment (22), as well as between economic status and visual impairment (23). Therefore, increasing eye care in people with hypertension and facilitating delivery of preventive, diagnostic and therapeutic care services for people with poor ES can help to reduce the economic inequality in PVA.

The second component, that is, adjustment of initial PVA toward PVA*, a more unfavourable state, had the highest contribution to PVA inequality changes. This indicated that the changes in PVA from the first to the second phase of the study resulted in a reduced gap between the initial PVA and PVA. The negative sign of the mobility index for this component shows that, firstly, this change led to an increase in $M^{\mathrm{PVA}}$ index and 
Figure 2 Gap between presenting vision acuity in 2009 and presenting vision acuity in steady state according to quintiles of economic status in 2009, Shahroud, Islamic Republic of Iran.

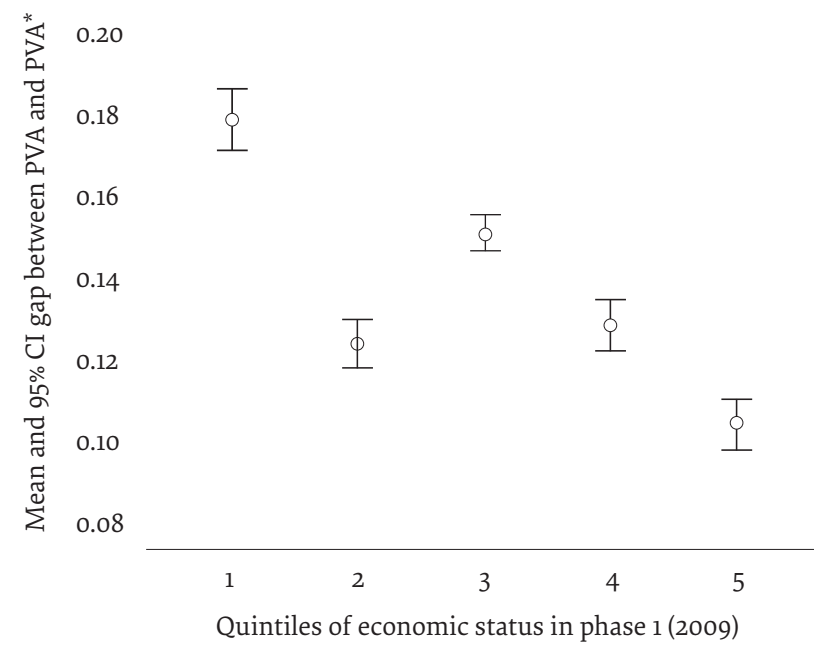

$C I=$ confidence interval $P$ PVA = presenting visual acuity

consequently helped to reduce inequality in PVA; and secondly, the highest level of adjustment of initial PVA towards PVA* occurred among more affluent people. In this component, the largest contribution was related to the age variable. Thus, the most important factor contributing to the reduction in economic inequality in PVA was the PVA score nearing its expected value in the equilibrium steady state in rich individuals due to their ageing. Therefore, the observed decline in economic inequality in PVA during the study did not result from a favourable change, such as improvement in visual acuity in poorer people; on the contrary, the change in PVA of richer people toward $\mathrm{PVA}^{*}$ was the most important factor contributing to the reduction in inequality in PVA. In other words, at the beginning of the study, the poorer people were older than the richer people and other risk factors for visual impairment, such as sex (being female) and lower education, were more concentrated among them, and consequently they had more unfavourable PVA. During the study, with the increase in the age of the participants, the status of the poorer people in terms of PVA remained almost stable. In contrast, the richer people experienced an increase in PVA score because of ageing and other factors. Hence, the gap between poor and rich people in terms of PVA decreased.

The most important strengths of this study were: the use of data obtained from a well-designed cohort study with carefully and continuously monitored data collection and considerable sample size to analyse the changes in inequality in a health outcome over time; the high response rate of the participants in both phases of the study; and applying a longitudinal data-based technique for analysis of over-time inequality changes. Nevertheless, the focus of our research on people aged 40-64 years could affect generalizability of the results.

\section{Conclusion}

This study showed a decrease in the economic inequality in PVA over a 5-year period. Although this reduction seemed to be a desirable change, longitudinal analysis revealed that this reduction in inequality was due to the deterioration of PVA in people with better ES and, consequently, the decrease in the difference between those with a poor ES and those with a better ES in terms of PVA. Therefore, we suggest that it is desirable to consider the needs of all socioeconomic groups when designing prevention and treatment programmes for visual impairment, to specifically modify visual acuity in each group and, consequently, reduce the economic inequality in visual acuity.

Funding: This work was supported by the Tehran University of Medical Sciences as a PhD thesis under Grant number 240/811. This study also is supported by Noor Eye Hospital and Shahroud University of Medical Sciences (Project numbers 8737 and 9826).

Competing interests: None declared. 


\section{Changement paradoxal dans l'inégalité économique en matière de correction des vices de réfraction entre 2009 et 2014 : une baisse non significative \\ Résumé}

Contexte: Malgré l'importance de la littérature, les inégalités en matière de santé et leurs déterminants, les changements observés dans ce domaine au fil du temps n'ont pas fait l'objet de suffisamment d'attention.

Objectifs: Mesurer et décomposer les changements survenus au fil du temps en matière d'inégalités économiques dans l'acuité visuelle à l'examen mesurée à l'aide du logarithme de l'angle minimal de résolution.

Méthodes: Nous avons analysé 4706 participants qui disposaient de données complètes sur l'acuité visuelle à l'examen et le statut économique en 2009 et 2014 dans l'étude de cohorte oculaire de Shahroud. Nous avons mesuré les changements dans les indices de concentration pour l'acuité visuelle à l'examen et les avons décomposés en utilisant une approche longitudinale.

Résultats : L'acuité visuelle à l'examen et le statut économique se sont tous deux détériorés entre 2009 et 2014. Les scores moyens (écart-type) pour l'acuité visuelle à l'examen et le statut économique présentés en 2009 par rapport à 2014 étaient de $0,090(0,2)$ contre $0,103(0,2)$ et de $0,01(1,0)$ contre $0,0005(1,07)$, respectivement. L'indice de concentration pour l'acuité visuelle à l'examen (intervalle de confiance à $95 \%$ ) dans la première et la deuxième phase de l'étude était de $-0,245(-0,212$ à $-0,278)$ contre $-0,195(-0,165$ à $-0,225)$, respectivement. La décomposition longitudinale de ce changement dans les indices de concentration au cours de la période de cinq ans a indiqué que l'élément le plus important contribuant à la réduction de l'inégalité économique de l'acuité visuelle à l'examen était la détérioration de celle-ci chez les personnes ayant un statut économique plus élevé à cause de leur vieillissement.

Conclusion: De manière inattendue, la réduction de l'inégalité économique dans l'acuité visuelle à l'examen était due à la détérioration de cette dernière dans le groupe de statut économique supérieur plutôt qu'à son amélioration dans le groupe de statut économique inférieur. Les besoins de tous les groupes socio-économiques doivent donc être considérés séparément pour modifier l'acuité visuelle à l'examen dans chaque groupe et, par conséquent, réduire l'inégalité économique.

$$
\begin{aligned}
& \text { التغير التَّاقٌّي في التفاوت الاقتصادي في تصحيح الانكسار البصري بين عامي } 200 \text { و و } 2014 \text { 2: انخفاض غير مفيد } \\
& \text { آسيه منصوري، محمد حسن إماميان، حجت زراعتى، حسن هاشمي، أكبر فتوحي لتصني }
\end{aligned}
$$

$$
\begin{aligned}
& \text { الخلفية: رغم انتشار الوعي بعدم المساواة الصحية ومُحدِّداتها، لم تحظَ التغيرات في عدم المساواة الصحية على مر الزمن بالاهتحام الكافي. }
\end{aligned}
$$

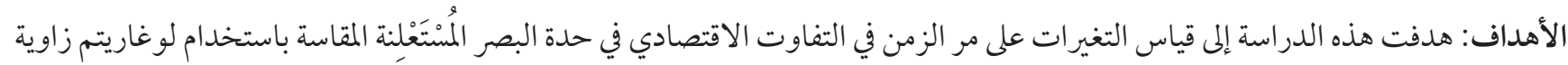

$$
\begin{aligned}
& \text { الوضوح الصغرى، وتحليلها. }
\end{aligned}
$$

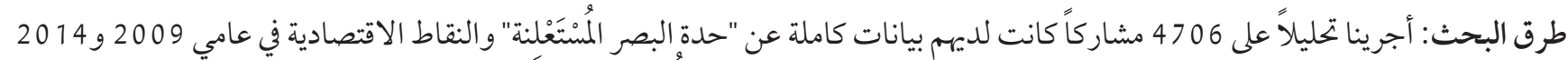

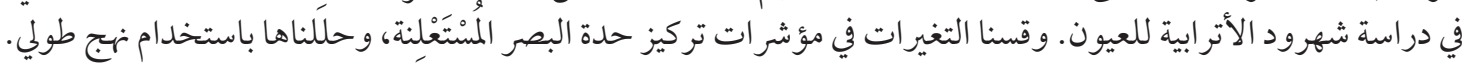

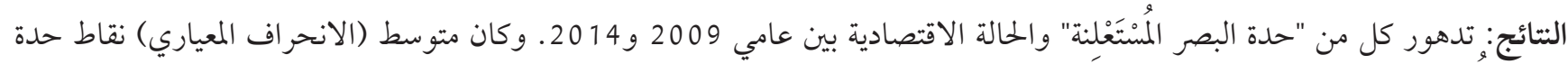

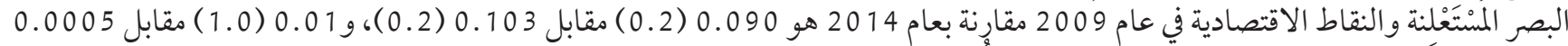

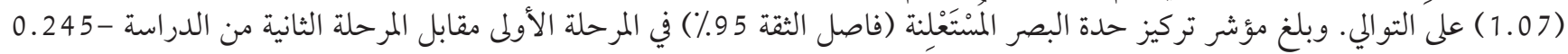

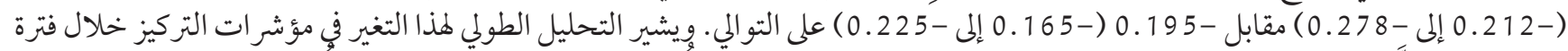

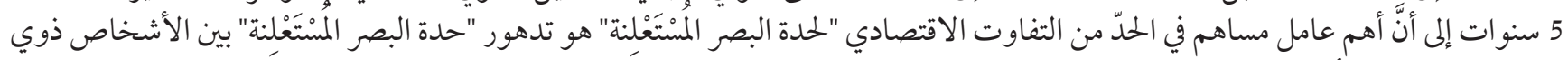
النقاط الاقتصادية الأعلى نظرًا لتقدمهم في في السن.

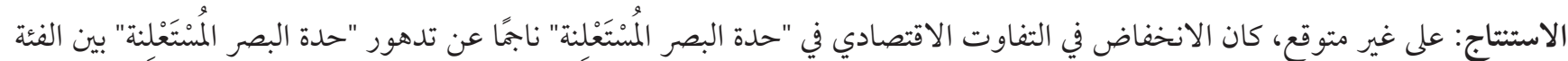

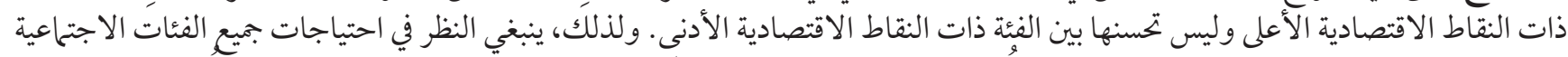

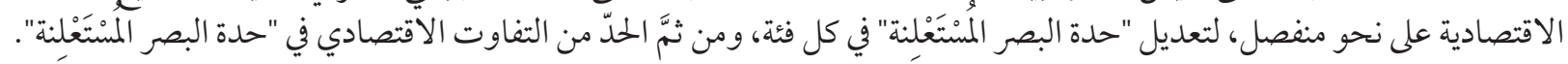




\section{References}

1. Kakwani N, Wagstaff A, Van Doorslaer E. Socioeconomic inequalities in health: measurement, computation, and statistical inference. J Econom 1997;77(1):87-103.

2. Petrie D, Allanson P, Gerdtham UG. Accounting for the dead in the longitudinal analysis of income-related health inequalities. J Health Econ. 2011 Sep;30(5):1113-23. https://doi.org/10.1016/j.jhealeco.2011.07.004 PMID:21820193

3. Allanson P, Petrie D. Longitudinal methods to investigate the role of health determinants in the dynamics of income-related health inequality. J Health Econ. 2013 Sep;32(5):922-37. https://doi.org/10.1016/j.jhealeco.2013.07.001 PMID:24036199

4. Combes JB, Gerdtham UG, Jarl J. Equalisation of alcohol participation among socioeconomic groups over time: an analysis based on the total differential approach and longitudinal data from Sweden. Int J Equity Health. 2011 Feb;10(10):1-15. https://doi. org/10.1186/1475-9276-10-10 PMID:21306654

5. Kim CO. Discrimination-related health inequality and role of social capital among marriage migrant women in South Korea. Int J Equity Health. 2016;15,176. https://doi.org/10.1186/s12939-016-0464-z

6. Kien VD, Lee H-Y, Nam Y-S, Oh J, Giang KB, Minh HV. Trends in socioeconomic inequalities in child malnutrition in Vietnam: findings from the Multiple Indicator Cluster Surveys, 2000-2011. Global Health Action. 2016 Feb 29;9(1):29263. https://doi. org/10.3402/gha.v9.29263 PMID:26950558

7. Wagstaff A, Van Doorslaer E, Watanabe N. On decomposing the causes of health sector inequalities with an application to malnutrition inequalities in Vietnam. J Econom. 2003 Jan;112(1):207-23. https://doi.org/10.1016/S0304-4076(02)00161-6

8. Emamian MH, Zeraati H, Majdzadeh R, Shariati M, Hashemi H, Fotouhi A. Economic inequality in presenting vision in Shahroud, Iran: two decomposition methods. Int J Health Policy Manag. 2017 Jan 1;7(1):59-69. https://doi.org/10.15171/ijhpm.2017.48 PMID:29325403

9. Allanson P, Petrie D. On decomposing the causes of changes in income-related health inequality with longitudinal data. Dundee Discussion Papers in Economics. 2011. Working Paper No. 250. https://discovery.dundee.ac.uk/en/publications/on-decomposingthe-causes-of-changes-in-income-related-health-ine

10. Chong EW, Lamoureux EL, Jenkins MA, Aung T, Saw S-M, Wong TY. Sociodemographic, lifestyle, and medical risk factors for visual impairment in an urban asian population: the singapore malay eye study. Arch Ophthalmol. 2009 Dec;127(12):1640-7. https://doi.org/10.1001/archophthalmol.2009.298 PMID:20008720

11. Cockburn N, Steven D, Lecuona K, Joubert F, Rogers G, Cook C, et al. Prevalence, causes and socio-economic determinants of vision loss in Cape Town, South Africa. PloS One. 2012;7(2):e30718. https://doi.org/10.1371/journal.pone.0030718 PMID:22363476

12. Zhang X, Cotch MF, Ryskulova A, Primo SA, Nair P, Chou C-F, et al. Vision health disparities in the United States by race/ethnicity, education, and economic status: findings from two nationally representative surveys. Am J Ophthalmol. 2012 Dec;154(6 Suppl):S53-62. https://doi.org/10.1016/j.ajo.2011.08.045 PMID:23158224

13. Emamian MH, Zeraati H, Majdzadeh R, Shariati M, Hashemi H, Fotouhi A. The gap of visual impairment between economic groups in Shahroud, Iran: a Blinder-Oaxaca decomposition. Am J Epidemiol. 2011 May 3;173(12):1463-7. https://doi.org/10.1093/ aje/kwro5o PMID:21540323

14. Emamian MH, Zeraati H, Majdzadeh R, Shariati M, Hashemi H, Fotouhi A. Unmet refractive need and its determinants in Shahroud, Iran. Int Ophthalmol. 2012 Aug;32(4):329-36. https://doi.org/10.1007/s10792-012-9567-8 PMID:22552579

15. Emamian MH, Zeraati H, Majdzadeh R, Shariati M, Hashemi H, Jafarzadehpur E, et al. Economic inequality in presenting near vision acuity in a middle-aged population: a Blinder-Oaxaca decomposition. Br J Ophthalmol. 2013 Sep;97(9):1100-3. https://doi. org/10.1136/bjophthalmol-2013-303249 PMID:23636851

16. Fotouhi A, Hashemi H, Shariati M, Emamian MH, Yazdani K, Jafarzadehpur E, et al. Cohort Profile: Shahroud Eye Cohort Study. Int J Epidemiol. 2013 Oct;42(5):1300-8. https://doi.org/10.1093/ije/dys161 PMID:23081880

17. Williams B, Onsman A, Brown T. Exploratory factor analysis: A five-step guide for novices. Aust J Paramed. 2010;8(3). https://doi. org/10.33151/ajp.8.3.93

18. Vyas S, Kumaranayake L. Constructing socio-economic status indices: how to use principal components analysis. Health Policy Plan. 2006 Nov;21(6):459-68. https://doi.org/10.1093/heapol/czlo29 PMID:17030551

19. Kakwani N, Wagstaff A, Van Doorslaer E. Socioeconomic inequalities in health: measurement, computation, and statistical inference. J Econometrics. 1997 Mar;77(1):87-103. https://doi.org/10.1016/S0304-4076(96)01807-6

20. Rius A, Artazcoz L, Guisasola L, Benach J. Visual impairment and blindness in spanish adults: geographic inequalities are not explained by age or education. Ophthalmology 2014 Jan;121(1):408-16. https://doi.org/10.1016/j.ophtha.2013.07.017 PMID:24053998

21. Cumberland PM, Rahi JS. Visual health inequalities: findings from UK Biobank. Lancet. 2014;384:S27. https://doi.org/10.1016/ So140-6736(14)62153-X

22. Allanson P, Gerdtham UG, Petrie D. Longitudinal analysis of income-related health inequality. J Health Econ. 2010;29(1):78-86. https://doi.org/10.1586/14737167.2016.1123096 PMID:26588093

23. Wong T, Mitchell P. The eye in hypertension. Lancet. 2007 Feb 3;369(9559):425-35. https://doi.org/10.1016/So140-6736(07)60198-6 PMID:17276782

24. Zebardast N, Friedman DS, Vitale S. The prevalence and demographic associations of presenting near-vision impairment among adults living in the United States. Am J Ophthalmol. 2017 Feb;174:134-44. https://doi.org/10.1016/j.ajo.2016.11.004 PMID:27865728 